\title{
O papel do Psicólogo ${ }^{1}$
}

\author{
Ignácio Martín-Baró
}

O trabalho profissional do psicólogo deve ser definido em função das circunstâncias concretas da população a que deve atender. A situação atual dos povos centro-americanos pode ser caracterizada por: (a) a injustiça estrutural, (b) as guerras ou quase-guerras revolucionárias, e (c) a perda da soberania nacional. Ainda que o psicólogo não seja chamado para resolver tais problemas, ele deve contribuir, a partir de sua especificidade, para buscar uma resposta. Propõe-se como horizonte do seu quefazer a conscientização, isto é, ele deve ajudar as pessoas a superarem sua identidade alienada, pessoal e social, ao transformar as condições opressivas do seu contexto. Aceitar a conscientização como horizonte não exige tanto mudar o campo de trabalho, mas a perspectiva teórica e prática a partir da qual se trabalha. Pressupõe que o psicólogo centro-americano recoloque seu conhecimento e sua práxis, assuma a perspectiva das maiorias populares e opte por acompanhá-las no seu caminho histórico em direção à libertação.

\section{O contexto centro-americano}

$\mathrm{E}$ xiste uma crescente consciência entre os psicólogos latino-americanos de que, na hora de definir a nossa identidade profissional e o papel que devemos desempenhar em nossas sociedades, é muito mais importante exami- 
nar a situação histórica de nossos povos e suas necessidades do que estabelecer o âmbito específico da psicologia como ciência ou como atividade. Percebe-se cada vez com maior clareza que as definições genéricas procedentes de outros lugares trazem uma compreensão de nós mesmos e dos outros muitas vezes míope diante das realidades que a maioria dos nossos povos enfrenta e são inadequadas para captar sua especificidade social e cultural. Assim, com relação à questão do papel do psicólogo no contexto atual da América Central, antes de perguntarmos sobre o quefazer específico do psicólogo, devemos voltar nossa atenção para esse contexto, sem presumir que o fato de fazermos parte dele torna-o suficientemente conhecido, ou que nele viver o converte automaticamente no referente de nossa atividade profissional.

Em uma caracterização superficial e passando por cima de diferenças importantes, podemos estabelecer três aspectos primordiais que parecem caracterizar o momento atual dos povos centro-americanos: a situação estrutural de injustiça, os processos de confrontação revolucionária e a acelerada conversão das nações em satélites dos Estados Unidos.

\section{A injustiça estrutural}

Em primeiro lugar, frente aos diagnósticos que pretendem atribuir os problemas da América Central à recente confrontação entre Leste e Oeste, e a subida ao poder do governo sandinista, e necessário insistir que os problemas fundamentais da área centro-americana são devidos a uma estruturação injusta de seus sistemas sociais (Torres Rivas, 1981; Rosenthal, 1982). Sobre sociedades pobres e subdesenvolvidas assentam-se regimes que distribuem desigualmente os bens disponíveis, submetendo a maioria dos povos a condições miseráveis que permitem a pequenas minorias desfrutar de todo tipo de comodidade e luxo (para um caso paradigmático, ver Sevilla, 1984). Na América Central, a maior parte do povo nunca teve suas necessidades mais básicas de alimentação, moradia, saúde e educação satisfeitas, e o contraste entre essa situação miserável e a superabundância das minorias oligárquicas constitui- 
se na primeira e fundamental violação aos direitos humanos em nossos países. A manutenção secular desta situação só tem sido possível graças à aplicação de mecanismos violentos de controle e repressão social, que tem impedido ou frustrado todo esforço histórico para mudar e mesmo reformar estruturas sociais mais opressivas e injustas (ver, para o caso da Guatemala, Aguilera et al., 1981).

Sem dúvida, existem diferenças notórias entre a situação da Costa Rica, por exemplo, que conseguiu desenvolver sistemas escolar e de assistência sanitária consideráveis, e a de Honduras, onde os serviços escolar e de saúde atingem uma reduzida parcela da população. Contudo, também entre os costariquenhos se observam profundas diferenças, a existência de amplos setores marginais frente a minorias oligárquicas, vastos núcleos da população submetidos à exploração e à miséria, que fazem de Costa Rica uma irmã e companheira de destino das outras nações da América Central.

\section{A luta revolucionária}

Uma segunda característica é a situação de guerra ou quase-guerra em que vivem todos os países da região. Existe uma sangrenta guerra civil em El Salvador, que já fez mais de 60.000 vítimas e desalojou $20 \%$ da população civil de seus lugares de origem. Há uma guerra não menos sangrenta nas fronteiras da Nicarágua, financiada e dirigida pelos Estados Unidos. Há uma situação difundida de guerrilha na Guatemala, resistindo a uma pavorosa campanha contra-insurreição. E há uma psicose de pré-guerra em Honduras, forçada pelo atual governo norte-americano a servir de porta-aviões à sua política bélica de contra-insurreição regional e, em um nível menor, talvez também em Costa Rica.

As conseqüências desse estado generalizado de guerra só podem ser adequadamente avaliadas quando se somam à situação de miséria estrutural, por si só catastrófica. Nestes últimos anos, o desenvolvimento econômico da área centro-americana não somente estacionou, como certamente retrocedeu. No caso de El Salvador, estimativas otimistas calculam que o retrocesso da economia nacional é de 
pelo menos vinte anos e que, no melhor dos casos e na mais favorável das projeções, o país poderia recuperar no final do século a situação em que se encontrava no momento em que começou a guerra (ver Instituto, 1983; Argueta, 1985; Ibisate, 1985). Economias por si só débeis, como a salvadorenha ou a nicaraguense, se vêem forçadas a dedicar a maior parte de suas reservas ao esforço bélico, isto é, à destruição de seu próprio povo e de seu próprio país. Onde deveriam surgir fábricas, constróem-se quartéis, e onde o dinheiro deveria ser investido em sementes e tratores, é usado para bombas e helicópteros armados.

A militarização da área centro-americana é um dos processos mais graves que estamos presenciando (Bermudez, 1985; Bermudez \& Cordova, 1985). Se El Salvador tem enfrentado durante mais de 50 anos um regime de exploração opressiva sob a administração das Forças Armadas que, em 1979, contava com mais ou menos 15.000 homens e 300 oficiais, o que fará no futuro com um exército que, neste momento, conta com 50.000 homens mais 15.000 membros dos chamados "corpos de segurança" e aproximadamente 2.300 oficiais, e que aspira a chegar aos 100.000 homens em um futuro muito próximo? Adicione-se a essas cifras, o número de guerrilheiros, provavelmente não menor que 10.000 , tão ou mais militarizados que o exército governamental, e grupos paramilitares armados pelo governo ou setores de extrema direita, e teremos uma patética perspectiva da situação de El Salvador. A situação não é melhor na Nicarágua ou na Guatemala. Honduras, como é sabido, foi convertida em um campo militar norte-americano, com gigantescas manobras militares sucedendo-se uma às outras, e com o câncer dos "contras" antisandinistas que, por razões logísticas óbvias, não podem conformar-se em permanecer na fronteira com a Nicarágua. E a Costa Rica? Costa Rica, assediada pela crise econômica e com sua dose de "contras", também está se deixando militarizar aceleradamente pelo belicismo de Reagan. Um dia, que temo ser muito breve, despertando de seu estupor anti-sandinista, irá descobrir, sem saber ou querer, que já tem um verdadeiro exército a quem alimentar e a quem manter feliz e ocupado. 


\section{Estados nacionais como satélites dos Estados Unidos}

A terceira característica da situação atual da América Central é a sua acelerada satelitização nacional. Trata-se de uma consequiência óbvia da doutrina da "segurança nacional", segundo a qual toda a existência dos países deve submeter-se à lógica da confrontação total frente ao comunismo (ver Mattelart, 1978; Insulza, 1982). Certamente, a América Central tem sido durante este século, parte do quintal norte-americano e, em nenhum momento, constituiu-se em uma ironia afirmar, como o fazia o poeta salvadorenho Roque Dalton, que "o presidente dos Estados Unidos é mais presidente do meu país que o presidente do meu país". Não obstante, os avatares da política norte-americana permitiram momentos em que os países da área desfrutaram de uma certa autonomia, ao menos na sua política interna (ver Maira, 1982). Esses "graus de liberdade", se me permitem a expressão, estão sendo eliminados rapidamente. Dir-se-ia que os governantes centro-americanos repetem hoje o que há vinte anos expressava com grande clareza o general Castelo Branco, sobre o golpe de estado que instalou no Brasil um dos regimes militares mais repressivos da história do continente sul-americano: "o caráter crítico do momento exige o sacrifício de uma parte da nossa soberania nacional" (Mattelart, 1978, p. 56).

O caso de El Salvador é paradigmático, mas não é exceção. Como demonstram as vicissitudes do processo de Contadora, a Costa Rica, El Salvador e Honduras só resta interpretar as músicas compostas em Washington, com os instrumentos fabricados em Washington, e para satisfazer os gostos de Washington. Aceitar que a pobreza de nossos países contém uma certa dependência daqueles que podem nos ajudar a enfrentar os nossos problemas não é tão ruim; o que é pior é que estamos hipotecando nossa própria identidade e autonomia sem com isso resolver nossos problemas, até mesmo eliminando a possibilidade de um futuro para os nossos povos. As grandes decisões políticas de nossos países são tomadas em função da segurança nacional dos Estados Unidos, não das necessidades dos nossos povos, com a justificativa de que São Salvador ou Manágua estão menos distantes de São Fran- 
cisco que Nova Iorque ou Boston. Essa mesma exigência de "segurança nacional" dos Estados Unidos intensifica a polarização já existente em nossos países, já que o mundo é automaticamente dividido em bons e maus, amigos e inimigos, sem que nada nem ninguém possa escapar dessa dicotomia maniqueísta (ver Martín-Baró, 1983). Perguntamo-nos, então, o que aconteceria se os Estados Unidos atingissem os seus objetivos de "segurança nacional" na região? Iria dedicar parte de sua atenção à resolução dos problemas mais graves dos nossos povos? Iria nos ajudar a construir a justiça em nossas sociedades, apoiando o desmantelamento das estruturas militares desnecessárias? Ou iria suspender o fluxo de dólares, satisfeito com a aniquilação dos movimentos revolucionários, mas obrigando-nos a manter todo o aparato de contra-insurreição, a fim de evitar problemas futuros para a sua segurança nacional?

A injustiça estrutural, as guerras revolucionárias e a satelitização nacional nos permitem caracterizar, em linhas gerais, a situação atual da América Central e oferecem-nos assim esse contexto histórico frente ao qual e no qual devemos definir o papel que corresponde ao psicólogo desempenhar.

\section{O papel do psicólogo}

Há alguns anos atrás, em 1968, um psicólogo francês, Marc Richelle, se colocava a questão "para que psicólogos?” A razão deste questionamento radicava no que ele qualificava de uma repentina e "inquietante proliferação de uma espécie nova" (Richelle, 1968, p. 7). Naquela mesma época, outro francês, Didier Deleule, dava uma resposta bastante radical a essa questão: a proliferação da psicologia se devia à função que estava assumindo na sociedade contemporânea, ao converter-se em uma ideologia de reconversão. A psicologia oferecia uma solução alternativa para os conflitos sociais: tratavase de mudar o indivíduo preservando a ordem social ou, no melhor dos casos, gerando a ilusão de que talvez, ao mudar o indivíduo, também mudaria a ordem social, como se a sociedade fosse uma somatória de indivíduos (Deleule, 1972; ver também Bricht et al., 1973).

Para sermos sinceros, quando se examina de forma desapaixonada o lugar que algumas concepções psicológicas ocu- 
pam no discurso político e cultural dominante, ou quando se pondera sobre o papel desempenhado pela maior parte dos psicólogos em nossos países, não se pode deixar de conceder uma boa dose de razão a Deleule. O problema, obviamente, não pode ser visto na intenção subjetiva que podem ter os profissionais da psicologia em um determinado país, nem sequer, me atreveria a dizer, em sua opção política. O problema reside nas próprias virtualidades da psicologia como quefazer teórico-prático. Não se trata, portanto, de se perguntar o que pretende cada um fazer com a psicologia, mas antes e fundamentalmente, para onde vai, levado por seu próprio peso, o quefazer psicológico; que efeito objetivo a atividade psicológica produz em uma determinada sociedade (Martín-Baró, s. d.).

Entre as críticas que com maior freqüência são feitas aos psicólogos da América Central estão a de que a maioria dedica sua atenção predominante, quando não exclusiva, aos setores sociais mais ricos, e que sua atividade tende a centrar de tal maneira a atenção nas raízes pessoais dos problemas, que se esquecem dos fatores sociais (ver também Zúñiga, 1976). O contexto social converte-se assim em uma espécie de natureza, um pressuposto inquestionado, frente a cujas exigências "objetivas" o indivíduo deve buscar a solução para seus problemas de modo individual e "subjetivo". Com este enfoque e com esta clientela, não é de se estranhar que a psicologia esteja servindo aos interesses da ordem social estabelecida, isto é, que se converta em um instrumento útil para a reprodução do sistema (Braunstein et al., 1979).

Poder-se-ia dizer, e com razão, que todas as profissões em nossa sociedade encontram-se a serviço da ordem estabelecida, e que, nesse sentido, nossa profissão não seria uma exceção. Poder-se-ia também mostrar todos os casos de psicólogos que têm servido e que continuam servindo as causas populares e revolucionárias. Mas esses pontos mostram que, se tomamos como ponto de partida o que psicólogos fizeram ou estão fazendo, não poderemos desbordar uma idéia positivista que nos mostrará uma imagem factual mais ou menos satisfatória, mas que deixará de lado todas aquelas possibilidades que, historicamente, têm sido descartadas. Daí o imperativo de exa- 
minar não só o que somos, mas o que poderíamos ter sido, e sobretudo, o que deveríamos ser frente às necessidades de nossos povos, independentemente de contarmos ou não com modelos para isso. Cabe perguntar, por exemplo, se os psicólogos nicaragüenses continuam usando hoje os mesmos esquemas de trabalho que usavam no tempo de Somoza, ou se a mudança de clientela, a necessidade de atender aos setores populares, os levou a mudar também seus modelos conceptuais ou práxicos (Whitford, 1985).

Uma boa maneira de se abordar o exame crítico do papel do psicólogo consiste em voltar às raízes históricas da própria psicologia. Seria necessário reverter o movimento que levou a limitar a análise psicológica à conduta, isto é, ao comportamento enquanto observável, e dirigir de novo o olhar e a preocupação à "caixa preta" da consciência humana. A consciência não é simplesmente o âmbito privado do saber e sentir subjetivo dos indivíduos, mas, sobretudo, aquele âmbito onde cada pessoa encontra o impacto refletido de seu ser e de seu fazer na sociedade, onde assume e elabora um saber sobre si mesmo e sobre a realidade que lhe permite ser alguém, ter uma identidade pessoal e social. A consciência é o saber, ou o não saber sobre si mesmo, sobre o próprio mundo e sobre os demais, um saber práxico mais que mental, já que se inscreve na adequação às realidades objetivas de todo comportamento, e só condicionada parcialmente se torna saber reflexivo (ver Gibson, 1966; Baron, 1980).

A consciência, assim entendida, é uma realidade psicossocial, relacionada com a consciência coletiva de que falava Durkheim (1984). A consciência inclui, antes de tudo, a imagem que as pessoas têm de si mesmas, imagem que é o produto da história de cada um, e que obviamente, não é um assunto privado; mas inclui, também, as representações sociais (Banchs, 1982; Deconchy, 1984; Farr, 1984; Jodelet, 1984, Lane, 1985) e, portanto, todo aquele saber social e cotidiano que chamamos "senso comum", que é o âmbito privilegiado da ideologia (Martín-Baró, 1984b). Na medida em que a psicologia tome como seu objetivo específico os processos da consciência humana, deverá atender ao saber das pessoas sobre si mes- 
mas, enquanto indivíduos e enquanto membros de uma coletividade. O saber mais importante do ponto de vista psicológico não é o conhecimento explícito e formalizado, mas esse saber inserido na práxis quotidiana, na maioria das vezes implícito, estruturalmente inconsciente, e ideologicamente naturalizado, enquanto adequado ou não às realidades objetivas, enquanto humaniza ou não às pessoas, e enquanto permite ou impede os grupos e povos de manter o controle de sua própria existência.

É importante enfatizar que esta visão da psicologia não descarta a análise do comportamento. Não obstante, o comportamento deve ser visto à luz de seu significado pessoal e social, do saber que põe de manifesto, do sentido que adquire a partir de uma perspectiva histórica. Assim, por exemplo, aprender não é somente elaborar e reforçar uma seqüência de estímulos e respostas, mas sobretudo estruturar uma forma de relação da pessoa com seu meio, configurar um mundo onde o indivíduo ocupa um lugar e materializa seus interesses sociais. Trabalhar não é apenas aplicar uma série de conhecimentos e habilidades para satisfação das próprias necessidades; trabalhar é, antes e fundamentalmente, fazer-se a si mesmo, transformando a realidade, encontrando-se ou alienando-se nesse quefazer sobre a rede das relações interpessoais e intergrupais. Tanto em um quanto em outro caso, a formalidade do comportamento se vê permeada por um sentido que não é decifrável a partir da superfície mensurável, porém sem cuja compreensão pouco ou nada se entende da existência humana.

A luz desta visão da psicologia, pode-se afirmar que a conscientização constitui-se no horizonte primordial do quefazer psicológico. É possível que para alguns esta afirmação soe algo escapista, enquanto para outros pareça uma colocação demasiadamente comprometedora; alguns pensarão que se trata de uma restrição excessiva da psicologia, enquanto que outros talvez achem que se trata de introduzir a psicologia em terrenos que não lhe pertencem. Examinemos então esta proposta mais detalhadamente, já que alguns mal entendidos poderão decorrer do uso do termo conscientização, tão evocador da história contemporânea dos países latino-americanos.

Como é sabido, conscientização é um termo cunhado por Paulo Freire para caracterizar o processo de transformação 
pessoal e social que experimentam os oprimidos latino-americanos quando se alfabetizam em dialética com o seu mundo (Freire 1970, 1971, 1973; INODEP, 1973). Para Freire, alfabetizar-se não consiste simplesmente em aprender a escrever em papéis ou a ler a letra escrita; alfabetizar-se é sobretudo aprender a ler a realidade circundante e a escrever a própria história. O que importa não é tanto saber codificar e decodificar palavras estranhas, mas aprender a dizer a palavra da própria existência, que é pessoal mas, sobretudo, é coletiva. E, para pronunciar esta palavra pessoal e comunitária, é necessário que as pessoas assumam seu destino, que tomem as rédeas de sua vida, o que lhes exige superar sua falsa consciência e atingir um saber crítico sobre si mesmas, sobre seu mundo e sobre sua inserção nesse mundo.

O processo de conscientização supõe três aspectos:

a. o ser humano transforma-se ao modificar sua realidade. Trata-se, por conseguinte, de um processo dialético, um processo ativo que, pedagogicamente, não pode acontecer através da imposição, mas somente através do diálogo.

b. Mediante a gradual decodificação do seu mundo, a pessoa capta os mecanismos que a oprimem e desumanizam, com o que se derruba a consciência que mistifica essa situação como natural e se lhe abre o horizonte para novas possibilidades de ação. Esta consciência crítica ante a realidade circundante e ante os outros traz assim a possibilidade de uma nova práxis que, por sua vez, possibilita novas formas de consciência.

c. O novo saber da pessoa sobre sua realidade circundante a leva a um novo saber sobre si mesma e sobre sua identidade social. A pessoa começa a se descobrir em seu domínio sobre a natureza, em sua ação transformadora das coisas, em seu papel ativo nas relações com os demais. Tudo isso lhe permite não só descobrir as raízes do que é, mas também o horizonte do que pode chegar a ser. Assim, a recuperação de sua memória histórica oferece a base para uma determinação mais autônoma do seu futuro.

A conscientização não consiste, portanto, em uma simples mudança de opinião sobre a realidade, em uma mudança da subjetividade individual que deixe intacta a situação objeti- 
va; a conscientização supõe uma mudança das pessoas no processo de mudar sua relação com o meio ambiente e, sobretudo, com os demais. Não há saber verdadeiro que não seja essencialmente vinculado com um saber transformador sobre a realidade, mas não há saber transformador da realidade que não envolva uma mudança de relações entre os seres humanos.

Ao afirmar que o horizonte primordial da psicologia deve ser a conscientização, se está propondo que o quefazer do psicólogo busque a desalienação das pessoas e grupos, que as ajude a chegar a um saber crítico sobre si próprias e sobre sua realidade. Como conseqüência do viés da psicologia, assume-se como óbvio o trabalho de desalienação da consciência individual, no sentido de eliminar ou controlar aqueles mecanismos que bloqueiam a consciência da identidade pessoal e levam a pessoa a comportar-se como um alienado, como um "louco", ao mesmo tempo em que se deixa de lado o trabalho de desalienação da consciência social, no sentido de suprimir ou mudar aqueles mecanismos que bloqueiam a consciência da identidade social e levam a pessoa a comportar-se como um dominador ou um dominado, como um explorador opressivo ou um marginalizado oprimido. Se até o DSM III (American Psychiatric Association, 1983) reconhece que todo comportamento envolve uma dimensão social, o quefazer do psicólogo não pode limitar-se ao plano abstrato do individual, mas deve confrontar também os fatores sociais onde se materializa toda individualidade humana.

Ao assumir a conscientização como horizonte do quefazer psicológico, reconhece-se a necessária centralização da psicologia no âmbito do pessoal, mas não como terreno oposto ou alheio ao social, mas como seu correlato dialético e, portanto, incompreensível sem a sua referência constitutiva. Não há pessoa sem família, aprendizagem sem cultura, loucura sem ordem social; portanto, não pode tampouco haver um eu sem um nós, um saber sem um sistema simbólico, uma desordem que não se remeta a normas morais e a uma normalidade social.

Como remete a uma circunstância social e a uma história concretas, no nosso caso, as dos países centro-americanos, a concientização obriga à psicologia a dar respostas aos gran- 
des problemas de injustiça estrutural, de guerra e de alienação nacional que afligem a esses povos. Não se pode fazer psicologia hoje na América Central sem assumir uma séria responsabilidade histórica, isto é, sem tentar contribuir para mudar todas as condições que mantém as maiorias populares desumanizadas, alienando sua consciência e bloqueando o desenvolvimento de sua identidade histórica. Porém, é preciso fazê-lo como psicólogos, isto é, a partir da especificidade da psicologia como quefazer cientifico e prático.

Em primeiro lugar, a conscientização responde à situação de injustiça, promovendo uma consciência crítica sobre as raízes, objetivas e subjetivas, da alienação social. Uma simples consciência sobre a realidade não supõe, por si só, a mudança dessa realidade, mas dificilmente se avançará com as mudanças necessárias enquanto um véu de justificativas, racionalizações e mitos encubrir os determinismos últimos da situação dos povos centro-americanos. A conscientização não só possibilita, mas facilita o desencadeamento de mudanças, o rompimento com os esquemas fatalistas que sustentam ideologicamente a alienação das maiorias populares.

Em segundo lugar, o processo mesmo de conscientização supõe abandonar a mecânica reprodutora das relações de dominação-submissão, visto que só pode ser realizado através do diálogo. Em última instância, o processo dialético que permite ao indivíduo encontrar-se e assumir-se como pessoa supõe uma mudança radical das relações sociais, em que não existam opressores nem oprimidos, e isto diz respeito tanto à psicoterapia quanto à educação escolar, ao processo de produção em uma fábrica, ou ao trabalho cotidiano em uma instituição de serviço.

Finalmente, a tomada de consciência aponta diretamente ao problema da identidade tanto pessoal como social, grupal e nacional. A conscientização leva as pessoas a recuperar a memória histórica, a assumir o mais autêntico do seu passado, a depurar o mais genuíno do seu presente e a projetar tudo isso em um projeto pessoal e nacional. Mal pode um processo de aprendizagem, de orientação vocacional ou de aconselhamento terapêutico buscar o desenvolvimento ou a realiza- 
ção das pessoas se, ao mesmo tempo, não se projetar o indivíduo em seu contexto social e nacional e, por conseguinte, se ao mesmo tempo não se coloca o problema da sua autenticidade como membro de um grupo, parte de uma cultura, cidadão de um país.

É possível que para a maioria dos psicólogos a dificuldade não resida tanto em aceitar este horizonte para o seu quefazer, mas em visualizá-lo em termos práticos. O que significa conscientizar na e com a atividade psicológica? Tratase de aplicar alguma técnica particular? Deve-se incluir nos processos alguma forma de reflexão política? Significa mudar os tipos de testes empregados ou os temas daqueles que usamos? Devemos abandonar a terapia individual e realizar algo assim como ergoterapias coletivas? Tentaremos dar mais forma a esta tese com dois exemplos sobre como buscar a conscientização com a atividade psicológica.

É claro que um dos problemas mais graves com que se depara atualmente na América Central é o das vítimas de guerra: soldados e guerrilheiros feridos ou inválidos por toda a vida, traumatizados talvez pelas experiências vividas em campo de batalha; populações aterrorizadas pela experiência de bombardeios, as operações contra-insurreicionais ou as matanças "sanitárias"; testemunho de crueldades repressivas, vítimas das táticas do terror ou da tortura, crianças órfãs marcadas por fugas prolongadas em meio à violência bélica. Todos eles constituem essa população de deslocados ou refugiados, de filhos da repressão ou da guerra, cujo número cresce aceleradamente e alcança já uma cifra não inferior a dois milhões de centro-americanos (ver, por exemplo, Lawyers, 1984; Instituto, 1985). Sem dúvida, essa população não só tem necessidades materiais sérias de alimentação, teto, saúde e trabalho, mas também tem outras necessidades que, embora não tão prementes, não por isso menos graves, de desenvolvimento pessoal e relações humanizadoras, de amor e esperança em sua vida, de identidade e significação social (Peña, 1984). Por isso, um objetivo primordial da psicologia centro-americana no presente e futuro próximo, deve ser prestar atenção especial às vítimas da guerra, sejam elas quais forem. Essa atenção irá re- 
querer a abertura da clínica a grupos majoritários, que são os que mais estão sofrendo o impacto do conflito bélico.

Será que poderemos enfrentar esse gravíssimo problema das vítimas da guerra simplesmente estendendo a mais pessoas o alcance do trabalho da psicologia clínica realizado na atualidade? Não representaria essa opção um simples restabelecimento dos termos de uma realidade social que está precisamente na raiz do conflito que se vive? A atenção clínica às vítimas das guerras centro-americanas deve constituir-se em um processo conscientizador, um processo que devolva a palavra às pessoas, não somente como indivíduos, mas como parte de um povo. Isto significa que a psicoterapia deve apontar diretamente para o desaparecimento de uma identidade social cultivada sobre os protótipos de opressor e oprimido, e a configurar uma nova identidade das pessoas enquanto membros de uma comunidade humana, responsáveis por uma história (Martín-Baró, 1984a). A superação dos traumas da guerra deve incluir uma tomada de consciência sobre todas as realidades, coletivas e individuais, que estão na raiz da guerra. Assim, pois, uma psicoterapia conscientizadora deve constituirse em um processo que permita ao indivíduo afirmar sua identidade pessoal e social como parte de um movimento de afirmação coletiva e nacional.

Um bom número de psicólogos centro-americanos dedica-se à orientação escolar. Esse trabalho costuma se reduzir à aplicação mais ou menos sistemática de baterias de testes, com as quais se pretende conhecer o nível de desenvolvimento e o grau de aprendizagem de cada estudante, detectar seus possíveis problemas, assim como definir uma perspectiva adequada aos seus interesses e capacidades. O pressuposto implícito dessa atividade baseia-se em que a sociedade existente constitui o âmbito em cujo interior cada qual deve encontrar formas mais produtivas e satisfatórias de acordo com suas características e ideais pessoais. Trata-se, portanto, de se conseguir um acoplamento, uma adaptação entre cada indivíduo e a sociedade, que em nenhum momento põe em questão os esquemas básicos da convivência e, portanto, a determinação dos papéis sociais que devem ser assumidos. A orienta- 
ção escolar contribui, dessa maneira, para a reprodução do sistema estabelecido com seus esquemas de passividade e falta de criatividade, de domínio e submissão.

Um trabalho de orientação escolar conscientizador supõe um esforço para proporcionar a transmissão de esquemas sociais alternativos: a capacidade crítica e criativa dos alunos frente ao que a escola e a sociedade lhes oferecem, um estilo diferente de confrontar a vida social e laboral. Trata-se não somente de que os alunos aprendam com os currículos escolares planejados, mas sobretudo, que aprendam a confrontar a realidade de sua existência com um pensamento crítico. Assim como existe uma organização de "pequenos empresários", na qual se inicia os adolescentes à administração empresarial capitalista, poder-se-ia pensar em algo como laboratórios sobre a realidade nacional, nos quais os jovens se veriam confrontando diretamente as condições sociais da maior parte da população e poderiam refletir criticamente sobre elas.

O horizonte conscientizador tanto no trabalho clínico como no trabalho de orientação escolar suporia, sem dúvida alguma, uma importante mudança no quefazer profissional. Não se trata de abdicar do papel técnico que em ambos os casos, corresponde ao psicólogo; trata-se de despojar esse papel de seus pressupostos teóricos adaptacionistas e de suas formas de intervenção a partir de posições de poder. Para tanto, torna-se necessário elaborar uma visão conceptual diferente e, talvez, também novos métodos de diagnóstico e de intervenção. No campo clínico, algumas das iniciativas empreendidas pelo movimento da anti-psiquiatria podem lançar luzes sobre as mudanças necessárias que se teve que implantar no trabalho psiquiátrico como resultado de uma concepção distinta sobre a realidade do transtorno psíquico e, portanto, de uma práxis terapêutica distinta (ver Basaglia, 1972; Cooper, 1972; Moffat, 1975); na psicologia escolar, a própria experiência da educação conscientizadora, sobretudo em seu paralelo e em sua diferença com a proposta desescolarizadora (Illich, 1971; Reimer, 1973), permitem vislumbrar novas formas de orientação.

Em que consiste, então, essa nova colocação teórica e prática do trabalho psicológico conscientizador? Em nossa opini- 
ão, não se trata de abarcar exclusivamente uma área de trabalho, mas de se fixar um horizonte para o quefazer profissional, qualquer que seja a área em que se trabalhe. Por isso, as perguntas críticas que os psicólogos devem se formular a respeito do caráter de sua atividade e, portanto, a respeito do papel que está desempenhando na sociedade, não devem centrar-se tanto no onde, nas no a partir de quem; não tanto em como se está realizando algo, quanto em beneficio de quem; e, assim, não tanto sobre o tipo de atividade que se pratica (clínica, escolar, industrial, comunitária ou outra), mas sobre quais são as conseqüências históricas concretas que essa atividade está produzindo.

\section{Conclusão: uma opção histórica}

É claro que não é o psicólogo que será chamado para resolver os problemas fundamentais com que se defrontam os povos centro-americanos na atualidade. Pensar outra coisa seria enganar-se tanto a respeito do que é a psicologia, como a respeito dos problemas centro-americanos, e incorrer nesse psicologismo que ten sido justamente denunciado como uma ideologia de reconversão. Não está nas mãos do psicólogo, enquanto tal, mudar as injustas estruturas socioeconômicas de nossos países, resolver os conflitos armados ou resgatar a soberania nacional, servilmente penhorada aos Estados Unidos.

Não obstante, há uma tarefa importante que o psicólogo deve cumprir e que requer tanto o reconhecimento objetivo dos principais problemas que afligem os povos centro-americanos como a definição da contribuição específica do psicólogo em sua resolução. Pois se o psicólogo, por um lado, não é chamado a intervir nos mecanismos socio-econômicos que articulam as estruturas de injustiça, por outro é chamado a intervir nos processos subjetivos que sustentam e viabilizam essas estruturas injustas; se não lhe cabe conciliar as forças e interesses sociais em luta, compete a ele ajudar a encontrar caminhos para substituir hábitos violentos por hábitos mais racionais; e ainda que a definição de um projeto nacional autônomo não esteja em seu campo de competência, o psicólogo pode contribuir para a formação de uma identidade, pessoal e coletiva, que responda às exigências mais autênticas dos povos. 
É indubitável que nós, psicólogos centro-americanos, enfrentamos um desafio histórico para o qual provavelmente não fomos preparados. Contudo, não se trata de encontrar justificativas para nossas deficiências, mas de ver como podemos assumir nossa responsabilidade social (Martín-Baró, 1985). Três pontos parecem necessários a esse respeito:

1. O psicólogo centro-americano deve repensar a imagem de si mesmo como profissional. Não se pode continuar com a inércia dos esquemas teóricos já conhecidos ou das formas de atuar habituais; nosso saber psicológico deve ser confrontado com os problemas novos dos povos centro-americanos e com as questões que lhe são apresentadas. $\mathrm{O}$ caso das vítimas da guerra é talvez o mais agudo e urgente, porém não é o único, nem sequer, talvez, o mais radical.

2. É urgente assumir a perspectiva das maiorias populares. Sabemos, pela sociologia do conhecimento, que o que se vê da realidade e como se vê, depende de forma essencial do lugar social de onde se olha. Até agora o nosso saber psicológico alimentou-se fundamentalmente de uma análise dos problemas realizada a partir da perspectiva dos setores dominantes da sociedade. Não é provável e, talvez, nem sequer possível, que alcancemos uma compreensão adequada dos problemas mais profundos que atingem as maiorias populares se não nos colocamos, ainda que hermeneuticamente, em sua perspectiva histórica.

3. Talvez a opção mais radical com que se defronta a psicologia centro-americana hoje esteja na alternativa entre uma acomodação a um sistema social que pessoalmente nos tem beneficiado, ou uma confrontação crítica frente a esse sistema. Em termos mais positivos, a opção reside entre aceitar, ou não, acompanhar as maiorias pobres e oprimidas em sua luta por constituir-se como povo novo em uma terra nova. Não se trata de abandonar a psicologia; trata-se de colocar o saber psicológico a serviço da construção de uma sociedade em que o bem estar dos menos não se faça sobre o mal estar dos mais, em que a realização de alguns não requeira a negação dos outros, em que o interesse de poucos não exija a desumanização de todos. 


\begin{abstract}
The role of the psychologist. The professional work of the psychologist must be defined according to the concrete circumstances of the population that he or she must attend. The current situation of the peoples in Central America can be characterized as: (a) structural injustice, (b) the revolutionary wars or quasi-wars, and (c) the loss of national sovereignty. Even though the psychologist is not called to solve such problems, he or she must contribute, from his/her specificity, to look for an answer. Conscientización is proposed as the horizon of the psychologist's endeavor, which means to help people to overcome their alienated personal and social identity, by transforming the oppressive conditions of their context. To embrace conscientización as professional skyline does not necessarily require changing the field of work, but certainly the theoretical and practical approach from which one works. It assumes that the Central American psychologist relocates his or her knowledge and practice, adopting the standpoint of the popular majorities, and decides to follow them in their historical path towards liberation.
\end{abstract}

\title{
Referências
}

American Psychiatric Association. (1983). DSM-III Manual diagnóstico y estadístico de los trastornos mentales. (Tradução de Manuel Valdés Miyar, Claudi Udina Abelló, Joan Masana Ronquillo e Tomás de Flores i Formenti). Barcelona: Masson.

Aguilera Peralta, G., Imery, J. R., et al. (1981). Dialéctica del terror en Guatemala. San José: EDUCA.

Argueta Artillón, L. (1985). La economía de El Salvador en 1984. Algunos elementos de análisis. Boletín de Ciencias Económicas y Sociales (UCA, San Salvador), 8, 7-29.

Banchs, M. A. (1982). Las representaciones sociales: un enfoque europeo para el estudio de las cogniciones sociales. Boletín de la AVEPSO, 5, 23-25.

Barón, R. M. (1980). Contrasting approaches to social knowing: An ecological perspective. Personality and Social Psychology Bulletin, 6, 591-600.

Basaglia, F. (1972). La instituición negada. Informe de un hospital psiquiátrico. (Tradução de Jaime Pomar) Barcelona: Barral. 
Bermúdez, L. (1985). Centroamérica: la militarizaión en cifras. Cuaderno de trabajo del CINAS, 4, 35-51.

Bermúdez, L., \& Córdova, R. (1985). Estados Unidos: Centroamérica, cuatro años de intervención militar (1981-1984). Cuaderno de trabajo del CINAS, 4, 5-34.

Braunstein, N. A., Pasternac, M., Benedito, G., \& Saal, F. (1979), Psicología: ideología y ciencia. México: Siglo XXI.

Bricht, S., Calvo, I., Dimant, F., Pravaz, S., de Spolansky, M. T. C., Troya, E., Danis, J., Grego, B., Kaumann, I., Harari, R., Musso, E., Knobel, M., Malté, R., Ostrov, L., \& Palacios, I. (1973). El rol del psicólogo. Buenos Aires: Nueva Visión.

Cooper, D. (1972). Psiquiatria y antipsiquiatria (Tradução de Jorge Psiatigorsky). Buenos Aires: Paidós.

Deconchy, J.-P. (1984). Systemes de croyances et représentations ideologiques. In S. Moscovici (Ed.), Psychologie sociale. Paris: Presses Universitaires de France.

Deleule, D. (1972). La psicología, mito científico. (Tradução de Nuria Pérez de Lara \& Ramón García). Barcelona: Anagrama.

Durkheim, E. (1984). Las reglas del método sociológico. Buenos Aires: Dédalo (Originalmente publicada em 1895).

Farr, R. Z. M. (1984). Les representations sociales. In S. Moscovici (Org.), Psychologie sociale. Paris: Presses Universitaires de France.

Freire, P. (1970). Pedagogía del oprimido (Tradução de Jorge Melado). Montevidéu: Tierra Nueva.

Freire, P. (1971). La educación como práctica de la libertad. (Tradução de Lilián Ronzoni). Montevidéu: Tierra Nueva.

Freire, P. (1973). ¿Extensión o comunicación? La concientización en el medio rural. (Tradução de Lilián Ronzoni). Buenos Aires: Siglo XXI.

Gibson, J. J. (1966). The senses considered as perceptual systems. Boston: Houghton Mifflin.

Grimson, W. R. (1972). Sociedad de locos, experiencia y violencia en un hospital psiquiátrico. Buenos Aires: Nueva Visión.

Heyward, H., \& Varigas, M. (1973). Antipsiquiatría (Tradução de Quino). Madri: Fundamentos.

Ibisate, F. J. (1985). Características y resultados de la gestión económica, ECA, 43-440, 347-379.

Illich, I. (1971). Deschooling society. Harmondsworth, Middlezex: Penguin.

INODEP. (1973). El mensaje de Paulo Freire. Teoría y prática de la liberación. Madri: Marsiega.

Instituto de Investigaciones de la Universidad Centroamericana José Simeón Cañas. (1985). Investigación. Desplazadfos y refugiados salvadoreños. San Salvador: Universidad Centroamericana José Simeón Cañas. 
Instituto de Investigaciones Económicas. (1983). Hacia una economia de guerra: El Salvador 1982-1983. ECA, 415-416, 439-458.

Insulza, J. M. (1982). La crisis en Centroamérica y el Caribe y la seguridad de Estados Unidos. En CECADE y CIDE, Centroamérica: crisis y política internacional. México: Siglo XXI.

Jervis, G. (I981). Psiquiatria y sociedad. Madri: Fundamentos.

Jodelet, D. (1984). Représentation sociale: phénomènes, concept et théorie. In S. Moscovici (Ed.), Psychologie sociale. Paris: Presses Universitaires de France.

Lane, S. T. M. (1985). Linguagem, pensamento e representações sociais. In S. T. M. Lane \& W. Codo (Orgs.), Psicologia social: o homem em movimento. São Paulo: Brasiliense.

Lawyers Committee for International Human Rights and Americas Watch (1984). El Salvador's other victims: the war on the displaced. New York.

Maira, L. (1982). Fracaso y reacomodo de la política de Estsdos Unidos hacia Centroamérica. In L. Maira (Org.). La política de Reagan y la crisis en Centroamérica. San José: EDUCA.

Martín-Baró, I. (1983). La polarización social en El Salvador.ECA, 412, 129-142.

Martín-Baró, I. (1984a). Guerra y salud mental, ECA. 425-430, 503-514.

Martín-Baró, I. (1984b). Psicología social. V: Sistema y poder. San Salvador: Universidad Centroamericana José Simeon Cañas.

Martín-Baró, I. (s. d.) Etica psicológica. San Salvador: Universidad Centroamericana José Simeon Cañas (mimeo).

Martín-Baró, I. (1985). Conflicto social e ideología científica: de Chile a El Salvador. Conferência pronunciada em Caracas, em 9 de julho de 1985, no XX Congresso Interamericano de Psicología.

Mattelart, A. (1978). Ideología, información y Estado militar. In M. Mattelart \& A. Mattelart (Orgs.), Comunicación e ideologías de la seguridad. Barcelona: Anagrama.

Moffat, A. (1975). Psicoterapia del oprimnido. Ideología y técnica de la psiquiatría popular. Buenos Aires: ECRO.

Peña, J. O. (1984) Necesidades familiares en un grupo de desplazados. Boletín de Psicología (UCA, San Salvador), 13, 18-20.

Reimer, E. (1973). La escuela ha muerto. Alternativas en materia de educación. (Tradução de Ernesto Mayans). Barcelona: Barral.

Richelle, M. (1968). Pourquoi les psychologues? Bruxelas: Charles Dessart.

Rosenthal, G. (1982). Principales rasgos de la evolución de las economias centroamericanas desde la posguerra. En CECADE y CIDE. Centroamérica: crisis y política internacional. México: Siglo XXI.

Sevilla, M. (1984), Visión global sobre la concentración económica en El Salvador. Boletín de Ciencias Económicas y Sociales (UCA), San Salvador, 7, 155-190. 
Torres Rivas, E. (1981). Crisis del poder en Centroamérica. Ciudad Universitaria Rodrigo Facio, Costa Rica: EDUCA.

Whitford, D. J. (1985). Apuntes de algunos aspectos de la historia de la psicología en Nicaragua. Managua: Universidad Centroamericana.

Zúñiga, R. B. (1976). La sociedad en experimentación y la reforma social radical. El papel del científico social en la experiencia de la Unidad Popular. In I. Martín-Baró (Org.), Problemas de psicología social en América Latina. San Salvador: UCA.

\section{Nota}

${ }^{1}$ Conferência pronunciada em 4 de outubro de 1985, na Universidade de Costa Rica, publicada no Boletín de Psicología UCA, 1985, 3(17), 99112. Tradução para o português da Dra. Yayá M. de Andrade e revisão dos Drs. Oswaldo H. Yamamoto e José Q. Pinheiro, a partir do original salvadorenho [Martín-Baró, I. (1990). El papel del psicólogo en el contexto centroamericano. Revista de Psicología de El Salvador, IX(35), 53-70] e da versão em língua inglesa [Martin-Baró, I. (1994). The role of the psychologist. In A. Aron, \& S. Corne (Orgs.), The writings for a liberation psychology (pp. 33-46). Cambridge, MA: Harvard University Press (tradução para o inglês de Adrianne Aron)]. As traduções do espanhol e do inglês para o português foram autorizadas, respectivamente, pela UCA, El Salvador, e pela HUP, Cambridge, MA, EUA.

Ignácio Martín-Baró nasceu em Valladolid (Espanha) em 7 de novembro de 1942, ingressando na Companhia de Jesus no ano de 1959. Estuda Humanidades em Quito (Equador), obtendo o grau de Licenciado em Filosofia e Letras; bacharelado em Teologia em Eegenhoven (Bélgica); mestrado em Ciencias Sociais e doutorado em Psicologia Social e Organização em Chicago (EUA). Vinculado desde 1967 à UCA (Universidad Centroamericana José Simeón Canãs, El Salvador), visitante de diversas universidades, dedica sua vida à luta pela libertação em El Salvador, simultaneamente, no trabalho desenvolvido (em especial) com os trabalhadores do campo, e no meio acadêmico, com inúmeros escritos sobre psicologia social e politica. É brutalmente assassinado pelo esquadrão da morte da repressão salvadorenha no dia 16 de novembro de 1969. 